\title{
The Impact of the Healthy Services Quality on the Level of the Service Offered by the Jordanian Health Sector from the Perspective of the Patients: An Applied Study
}

\author{
Belal Mathani ${ }^{1}$, Hamdan Rasheed AL-Jamal ${ }^{1}$, Muhammed AL-Jabari ${ }^{1} \&$ Ameen AL-Basheer $^{1}$ \\ ${ }^{1}$ Ajalon National University, Ajalon, Jordan \\ Correspondence: Hamdan Rasheed AL-Jamal, Ajalon National University, Ajalon, Jordan. E-mail: \\ dr.hamdan_aljammal@yahoo.com
}

Received: May 19, 2015

Accepted: June 11, $2015 \quad$ Online Published: July 22, 2015

doi:10.5539/ijbm.v10n8p171

URL: http://dx.doi.org/10.5539/ijbm.v10n8p171

\begin{abstract}
In this paper we identify the impact of the dimensions of health services quality on the level of service offered in the Jordanian health sector from the patients' perspective through a case study undertaken at King Abdullah University Hospital, Jordan. Also to determine the relative importance of the elements and the dimensions of health services quality including: "tangibility, reliability, responsiveness, trust, and empathy". The study has dealt with the problem through the main following hypothesis: there is no statistical significant at $(\alpha=0.05)$ between the main dimension of the service quality (tangibility, reliability, responsiveness, trust, and empathy) and the level of health service offered at the hospital from the patients' perspectives. To achieve the objectives of the study, the descriptive analytical approach has been applied. The study has proven that there is a stastical significant between the variables of the study (dimensions) and the level of health services.
\end{abstract}

Keywords: quality management, comprehensive quality management, the management of health services, the dimensions of management of health services quality

\section{Introduction}

Realization of business organization increases on the different types for the importance and the role of applying the concept of management of comprehensive quality in achieving the competitive advantage in the light of the global challenges and information technology and other factors that obligate the institutions apply the scientific method to deal with the challenges. The environments of such are characterized in Permanent change. So, the business organizations adopt managerial concepts where the comprehensive quality management is the most important. The management of health services is important because it has an impact on all people involved in health care from patients to staff.

The health service sector in Jordan witnesses great expanding and growth recently, at the same time it becomes an area for competition among the many institutions that operate in the same sector. Efficiency of offering the services is done by identifying the needs of customers and their predictions about the services offered due to the exceptions of the clients.

Hence the study of how the health service institution through the application of standards and dimensions of Total Quality Management can improve the quality of service provided from the perspective of health institution which is now the ultimate goal for patients with organizations level problem. The main objectives of the study is to identify the nature of the elements of health service quality management at the health institutions, to identify the assessment of patients from the services of the hospital in return for the dimensions of service quality offered by the administration of the hospital and to determine the relative importance for the elements and dimensions of health service quality from the perspective of the patients.

The study tries to achieve the results by answering the following set of questions:

- Does the management of the hospital offer the dimensions of service quality?

- Is there an assessment for the quality of services offered by the hospital?

- Is there a disparity in the relative importance attached by the patients beneficiaries of the standards used when evaluating the level of quality of services offered to them? 
The significance of the study which took place King Abdullah University Hospital between 1/4/2014 to 12/2014 shows the importance of health services that may be observed by the main dimensions of quality which includes: tangibility, reliability, responsiveness, trust, and empathy.

To form a more accurate picture on the subject of study, the researchers tried to get previous studies. A good indication of the importance of the subject, an extensive relevant research was performed on the subject.

The study carried out (Diab, 2012) aimed to measure dimensions of health service quality offered at the public Jordanian hospitals from the perspectives of the employees and the patients. The researcher has selected a sample of patients and employees at three hospitals in northern and central south of the kingdom, and has developed two questionnaires one for employees and one for patients in order to gather information. The study showed that the public hospitals have an interest in applying the health service dimensions. There is no gap between the projected health services and health services actually provided.

In Ateeq (2012) the study aimed to identify the reality of health service quality at the public health institutions for the state of (Saeeda) through a sample poll consisted of (1110) patients at the hospital. The results of the study revealed that the hospital is committed to offer health services punctually and correctly for the first time and the hospital facilitates the work procedures as much as possible. However, most of the patients are dissatisfied with the services offered.

The results of study carried out in (Dalila, 2012) have shown that there are substantial obstacles in applying different orientation catalog components at public health institutions in Algeria. The study pointed out the difficulty in the transition from orientation to production in the conduct of these institutions.

The study of (AL-Anezi, 2011) aimed to identify the demands and the obstacles of applying the comprehensive quality management for the employees working in management of Medical Affairs Border Guard, to identify the employees' trends for applying the comprehensive quality management. The result of the study have shown the following: there is a high level of knowledge in the concepts of total quality management, and the overall quality application will contribute to improve the efficiency and performance of employees, and that the overall quality is applicable in the management of medical affairs. The study of (Bu-Qjane, 2010) aimed to identify the impact of health service quality on the degree of patients' loyalty at the Jordan university hospital. The results of the study have shown the following: The level of health service quality at the Jordanian university hospital was with high degree. While the quality of health services by using the gaps relatively weak scale level and by the fact that the quality expected by the hospital patients outweigh the perceived quality of them, and that the most important deportation component of quality prevailing in the hospital and health services, as measured by objective characteristics are respectively: After the quality of hotel services, the quality of administrative services medical staff quality, yet the quality of technical services, and the most important components of quality prevailing in the hospital health services, according to the measure gaps are respectively: After tangibility, after responding, after reliability, after confirmation, empathy.

The rest of the paper is organized as follows: we state the hypothesis of the study in section 2. In section 3, we explained the theoretical framework and back ground. Elements of health service quality management are explained in section 4. The methodology is in section 5 and the results of statistical analysis are stated in section 6. Finally the concluding remarks are in section 7.

\section{Hypothesis of the Study}

The main hypothesis of the study is that there is no statistical significant at $(\alpha=0.05)$ between the main dimension of services quality (tangibility, reliability, responsiveness, trust, and empathy) and the level the health service offered at the hospital from the perspectives of the patients. The main hypothesis can be further subdivided into five sub-hypothesis based on each element in the service quality as follows:

The sub-hypothesis (1): there is no statistical significant at $(\alpha=0.05)$ between the main dimension of tangibility and the level the health service offered at the hospital from the perspectives of the patients.

The sub-hypothesis (2): there is no statistical significant at $(\alpha=0.05)$ between the main dimension of reliability and the level the health service offered at the hospital from the perspectives of the patients.

The sub-hypothesis (3): there is no statistical significant at $(\alpha=0.05)$ between the main dimension of responsiveness and the level the health service offered at the hospital from the perspectives of the patients.

The sub-hypothesis (4): there is no statistical significant at $(\alpha=0.05)$ between the main dimension of trust and the level the health service offered at the hospital from the perspectives of the patients.

The sub-hypothesis (5): there is no statistical significant at $(\alpha=0.05)$ between the main dimension of empathy and 
the level the health service offered at the hospital from the perspectives of the patients.

\subsection{Theoretical Framework}

The Total Quality Management (TQM) is an inevitability urgent and timely need in the management of our life and our long run tendencies (Sarhan, 2012, p. 1). Philosophical framework for quality management is based on a set of ideas and principles that any organization can be applied in order to achieve the best possible performance and increase their profits. There are various definitions for quality. To mention some: "Quality is physical or non-physical characteristics which forms basic nature of something or it is one feature for something" (Hdad, 2009, p. 13). (Oakley, 2001, p. 17) defines quality as "organizations produces a sale or offer a service with high quality where it is able performing the needs and the wishes of the customers confirming with its predictions and achieving stratification and happiness by measures put before for producing the sale or offering service or implementing Excellency".

The total quality management includes "Continuous improvement of production processes; it is the process of exercising the managerial jobs in manufacturing processes which determines the specific technical style productive user type approach to ensure the organization to reach its goals" (Abdullah, 2013, p. 14). (Al-Nasani, 2003 , p. 2) pointed that there are three general approaches in defining (TQM). The first focuses on the customer which means developing the level of performance offered for customers through working on training and devolving the employees. The second approach focuses on the interest in development and modernism and sharing the modern and new techniques on the productivity process in order to reduce the cost of damaged and waste production cost to offer high-end products. The third approach focuses on the agreement (contract) which seeks for to comply with the agreed specifications of contract.

It could be argued that the total quality management reflects the strategic management system integrated to achieve customer satisfaction seeking through the participation of workers and using the methods and scientific methods in order to continuously improve the administrative process. It is a starting point for making a radical change in the organization and transform it from traditional one to modern one.

TQM is extremely important in health institutions and hospitals as it has a direct effect on human health and consequently affects the whole society performance and production. Every health institution in general and hospitals in particular must have a TQM system in order maintain its medical situation and its professional reputation. The total quality management is considered a umbrella includes high number of quality methods may be applied. The study will discuss some definitions indicating the concept of quality in the framework of health service, (Sufian) indicated that World Health Organization (WHO) has defined health service quality as "offering the diagnostic and therapeutic activities for every patient uniformly which grantees the best results in the area of health due to medicine wit best cost and less risks (Sufian, 2006, p. 5). (ALtweel) defined the quality of health services as "managerial philosophy of health centers where the needs of the patients and the aims of the centers are achieved" (ALtweel, 2010, p. 66). The quality of health services can be defined as an integrated method applied in the health department where the medical staff offers the chance of statisfication for patients and reviewers by the best methods and less cost.

The objectives of adopting health quality services management can be summarized as follows: (AL-Bakre, 2001, p. 373).

- Conducting a comprehensive and connected development at the organization.

- Achieving the process of quality by participating in all departments and managements and with all employees.

- Achieving the operations of quality control by designing the product and the process and the services after sales.

- Seeking for achieve the way of selecting suppliers according to number of comprehensive standards where the relation with them is determined, and it must be established due to participation

AL-Salmi (1995, p. 299) mentioned that institution by applying the total quality management seeks for offering high quality sales with less cost, thus achieving set of the following objectives:

- Developing the human resource and competencies.

- Increasing the productivity of the enterprise elements.

- Improving the efficiency of the institution.

- Achieving profitability and competitive potential at the market. 
We note here that all quality management objectives seek to improve quality by improving processes and thus increase productivity, which leads to lower product costs and thus increase the market share of the institution and thus increase the profits. It has been noticed the need to identify the goals of quality health services on the grounds of our study of one of the institutions that health services where parapet pointed out that the health institutions seeking to provide high-quality health services that would achieve the following objectives:

- Ensure the physical and mental health of patients.

- Provide quality health services would achieve high patient satisfaction and increase its commitment to the health center.

- Knowledge of the opinions and impressions of patients and measure the level of satisfaction and an important means of health services research in the field of management and planning of health services and policy development related to them.

- Develop and improve communication between patients and providers channels.

- Enable health centers to continue and grow and perform its functions effectively and efficiently (AL-Metras, 2009 , pp. 7-8), and we can say that the introduction of the principle of total quality health services to achieve the health of the institution to improve the morals of the employees and increases customer satisfaction, customers and achieve positive results on the level medical and adjusts the financial costs and eventually lead to retain talented employees

\subsection{Elements of Health Service Quality Management}

Dalila (2012, p. 101) indicates that quality requires demands and some conditions to be applied. One of the most important element is the need to pay attention to the internal and external customer and seek for analyzing and identifying their interests to achieve a particular ratio of statisfication. For that it was necessary to provide the appropriate infrastructure, organizational climate and adequate support and commitment of high management to apply quality programs.

AL-Enazi (2011) mentioned that there is an agreement among the researchers and thinkers about the elements of total quality in the health services including: commitment of managerial and medical leadership, finding the organizational trust, employees participation, client consternation, development of operations, management of data collection Periodically, and cost containment. (Abdullah, 2013, pp. 97-99) indicated that the elements of health service quality are the basic structure of the w management of health service which includes: Continuous development, Focus on patients, Managerial leadership, Total participation of employees and Taking decision based on facts and realty.

There are set of difficulties face patients in evaluating intangible service. However, they depend on the level of quality. Many studies discuss the dimensions for evaluating the services. Those dimensions includes: Reliability, Responsiveness, Tangibility, Courtesy and Trust.

\section{Methodology}

Analytical descriptive approach has been applied to deal with the topic. It is appropriate to study the social phenomena. It presents data about the reality of phenomena explaining the reasons and the results and the analysis. It identifies the factors effected in and it brings the results and recommendations related to the topic.

\subsection{Type of Data}

There are two types of data: Primary and secondary data. In all references whether books, scientific journals, or websites that related to the topic of the study, the researcher has agreed that the Primary data has been collected by a list of community survey applied on a sample. The list has been prepared basing on Likert Quintet Model allows to participant a freedom to express an opinion for any question freely and accurately. Response list starts from "strongly agree with" and ends "not strongly with". The list is consisted of (25) questions divided into five (5) sides are formed in order to reach to a faithful response by the patients and the reviewers of King Abdullah University Hospital about dimensions of health service quality on the level of service provided in the health Jordanian sector.

\subsection{Stability Tool of the Study}

Stability of the study has been verified by distributing the tool on a survey sample consisted of (400) reviewers outside the sample of the study twice for (two weeks) duration of time. Pearson Correlation has been extracted from their degrees. All the skills of the study and the tool have had statistical significant. This indicates that the tool of the study is verified completely. Cornbach Alpha equation has been applied to extract Reliability coefficient. 
Table 1. Reability coefficient by applying Pearson correlation and cornbach alpha equation

\begin{tabular}{lll}
\hline Field & Pearson correlation & Cornbach Alpha equation \\
\hline Reliability & 0.83 & $0.83^{*}$ \\
Tangibility & 0.89 & $0.81^{*}$ \\
Responsiveness & 0.88 & $0.86^{*}$ \\
Trust & 0.86 & $0.87^{*}$ \\
Courtesy & 0.84 & $0.88^{*}$ \\
Tool as a whole & 0.87 & $0.83^{*}$ \\
\hline
\end{tabular}

Note. A statistical significant at $(\alpha=0.05)$.

Table 1 shows Reability coefficients by Cornbach Alpha for the fields of the study were between (0.83-0.89). They are high degree and acceptable to be applied. Most studies have indicated that reability coefficient is (0.060).

Pearson Correlation was between (0.81-0.88). It is a statistical significant at $(\alpha=0.05)$. This indicates the tool of study is stable.

\subsection{Analysis Process (Methods)}

1) Cornbach Alpha: to verify reability tool of the study.

2) Pearson Correlation: to verify from stability of applying.

3) Means and Standard deviations: To identify the answers of sample individuals on the paragraphs of study tool.

4) One Sample T-test: to verify the hypothesis of study.

\subsection{Sample of Study}

It consists of (400) reviewers from both genders at King Abdullah University Hospital. They were randomly selected from study population. Table 2 shows distributing the individuals due to personal variables.

Table 2. Distributing the individuals due to personal variables

\begin{tabular}{|c|c|c|c|}
\hline Variable & Level & Frequency & Percentage \\
\hline \multirow[t]{3}{*}{ Gender } & Male & 206 & 51.5 \\
\hline & Female & 194 & 48.5 \\
\hline & Total & 400 & 100.0 \\
\hline \multirow[t]{5}{*}{ Age } & Less than 25 years & 115 & 28.8 \\
\hline & 25-30 years & 23 & 5.8 \\
\hline & 36- 45 years & 130 & 32.5 \\
\hline & Above 45 years & 132 & 33.0 \\
\hline & Total & 400 & 100.0 \\
\hline \multirow[t]{5}{*}{ Scientific qualification } & under graduates & 172 & 43.0 \\
\hline & Bachelor & 120 & 30.0 \\
\hline & Master degree & 91 & 22.8 \\
\hline & PH.D & 17 & 4.3 \\
\hline & Total & 400 & 100.0 \\
\hline \multirow[t]{5}{*}{ Duration for dealing in hospital } & Less than a year & 103 & 25.8 \\
\hline & $1-3$ years & 194 & 48.5 \\
\hline & 4- 5 years & 57 & 14.3 \\
\hline & Above 5 years & 46 & 11.5 \\
\hline & Total & 400 & 100.0 \\
\hline \multirow[t]{4}{*}{ Number of times of stay in hospital } & No stay & 206 & 51.5 \\
\hline & Once- -3 times & 148 & 37.0 \\
\hline & Above 3 times & 46 & 11.5 \\
\hline & Total & 400 & 100.0 \\
\hline
\end{tabular}

Table 2 shows number of males in the sample reached to (206) and percentage (51.5\%). Whereas, females (194) 
$(48.5 \%)$.

1) The highest percentage of individuals due to age was (33.0\%) for (above 46 years). Whereas, the lowest $(5.8 \%)$ for $(25-30)$ years.

2) The highest percentage of individuals due to scientific qualification was (34.0\%) for (under graduates ). Whereas, the lowest $(4.3 \%)$ for (doctorate).

3) The highest percentage of individuals due to duration for dealing in hospital was (48.5\%) for (1-3 years). Whereas, the lowest (11.05\%) for (above 5 years).

4) The highest percentage of individuals due to Number of times of stay in hospital was (51.5) for (no stay). Whereas, the lowest (11.5\%) for (above 3 times).

\section{The Results of Statistical Analysis}

Here, we provide results of study aimed to identify "the impact of health service quality dimensions on the level of service offered in the Jordanian health sector from the perspectives of patients". A case study at King Abdullah University Hospital.

The results related to sub-hypothesis (1):

There is no statistical significant at $(\alpha=0.05)$ between the main dimension of tangibility and the level the health service offered at the hospital from the perspectives of the patients.

To verify from hypothesis, means, standard deviations of sample individuals have been extracted on "tangibility" Table 3 shows.

Table 3. Means, standard deviations of sample individuals have been extracted on "tangibility"

\begin{tabular}{|c|c|c|c|c|c|}
\hline Rank & No. & Paragraph & Mean & Std. & Assessment degree \\
\hline 1 & 5 & $\begin{array}{l}\text { Paths at hospital are wide and comfortable to } \\
\text { make the patients passes freely. }\end{array}$ & 4.37 & 0.76 & High \\
\hline 2 & 3 & $\begin{array}{l}\text { There is an interest by management of hospital } \\
\text { and employees in cleaning. }\end{array}$ & 4.31 & 0.58 & High \\
\hline 3 & 1 & $\begin{array}{l}\text { The hospital has equipments and medical modern } \\
\text { devices. }\end{array}$ & 4.21 & 0.41 & High \\
\hline 4 & 2 & $\begin{array}{l}\text { The hospital offers attached services including } \\
\text { (pharmacy, parking). }\end{array}$ & 4.07 & 0.79 & High \\
\hline 5 & 4 & $\begin{array}{l}\text { The hospital puts advertisements and instructions } \\
\text { facilitate reaching to different departments }\end{array}$ & 4.06 & 0.76 & High \\
\hline \multicolumn{3}{|c|}{ The dimension of "tangibility" as a whole } & 4.21 & 0.46 & High \\
\hline
\end{tabular}

Table 3 shows that means of sample individuals were among (4.06-4.37) with high degree for all paragraphs. The highest was (5) Paths at hospital are wide and comfortable to make the patients passes freely. The lowest 4 The hospital puts advertisements and instructions facilitate reaching to different departments. Mean for the dimension as a whole (4.21) with high degree.

One Sample T-test was applied on the dimension of "tangibility". Table 4 shows that:

Table 4. Results of applying one sample T-test on the dimension of "tangibility"

\begin{tabular}{lllllll}
\hline Hypothesis & Std. & T & $\begin{array}{l}\text { Assessment } \\
\text { deg. }\end{array}$ & Std. & Mean & Result \\
\hline $\begin{array}{l}\text { Hypothesis } \\
\text { accepted }\end{array}$ & 0.00 & 22.02 & High & 0.46 & 4.21 & $\begin{array}{l}\text { there is no statistical significant at }(\alpha=0.05) \text { between the main dimension } \\
\text { of tangibility and the level the health service offered at the hospital from } \\
\text { the perspectives of the patients. }\end{array}$ \\
\hline
\end{tabular}

Table 4 shows that there is a stastical significant at $(\alpha=0.05)$ between the main dimension of tangibility and the level the health service offered at the hospital from the perspectives of the patients. (T) was (22.02) and it is a statistical significant. The standard mark for scale Quintet (3), mean was (4.21) and it is higher value than the standard mark. So, the hypothesis accepted by the proven formula not the alternative one. 
The results related to sub-hypothesis (2):

There is no statistical significant at $(\alpha=0.05)$ between the main dimension of reliability and the level the health service offered at the hospital from the perspectives of the patients.

To verify from hypothesis, means, standard deviations of sample individuals have been extracted on "reliability" Table 5 shows:

Table 5. Means, standard deviations of sample individuals on "reliablility"

\begin{tabular}{|c|c|c|c|c|c|}
\hline Rank & No. & Paragraph & Mean & Std. & Assessment degree \\
\hline 1 & 3 & $\begin{array}{l}\text { Management of hospital is interested in offering } \\
\text { service in limited time secretly and accurately. }\end{array}$ & 4.03 & 0.78 & High \\
\hline 2 & 5 & $\begin{array}{l}\text { Management of hospital is interested in writing } \\
\text { down information about patients and their status in } \\
\text { computer and records. }\end{array}$ & 3.90 & 0.89 & High \\
\hline 3 & 4 & $\begin{array}{l}\text { The hospital enjoys trust of patients and the users } \\
\text { of service. }\end{array}$ & 3.71 & 1.07 & High \\
\hline 4 & 1 & $\begin{array}{l}\text { Management of hospital is commitment in its } \\
\text { promise with patients in the field of offering health } \\
\text { and recovery services and the appropriate } \\
\text { environment satisfied. }\end{array}$ & 3.69 & 0.83 & High \\
\hline 5 & 2 & $\begin{array}{l}\text { The hospital responses fast for the problems and } \\
\text { ask of patients. }\end{array}$ & 3.66 & 0.74 & Medium \\
\hline \multicolumn{3}{|c|}{ The dimension of "reliability" as a whole } & 3.80 & 0.63 & High \\
\hline
\end{tabular}

Table 5 shows that means of sample individuals were among (3.66-4.03) with high degree for all paragraphs. The highest was (3) The hospital enjoys trust of patients and the users of service the lowest (2) Management of hospital is interested in writing down information about patients and their status in computer and records. Mean for the dimension as a whole (3.80) with high degree.

One Sample T-test was applied on the dimension of "reliability". Table 6 shows that:

Table 6. Results of applying one sample T-test on the dimension of "reliability"

\begin{tabular}{lllllll}
\hline Hypothesis & Sig. & T & Assessment deg. & Std. & Mean & Result \\
\hline $\begin{array}{l}\text { There is no statistical } \\
\text { significant at }(\alpha=0.05)\end{array}$ & & & & & \\
between the main dimension & & & & & \\
of reliability and the level the 0.00 & 10.51 & High & 0.63 & 3.80 & Hypothesis \\
health service offered at the & & & & \\
hospital from the \\
perspectives of the patients.
\end{tabular}

Table 6 shows that there is a stastical significant at $(\alpha=0.05)$ between the main dimension of reability and the level the health service offered at the hospital from the perspectives of the patients. (T) was (10.51) and it is a statistical significant. The standard mark for scale Quintet (3), mean was (3.80) and it is higher value than the standard mark. So, the hypothesis accepted by the proven formula not the alternative one.

The results related to sub-hypothesis (3): there is no statistical significant at $(\alpha=0.05)$ between the main dimension of responsiveness and the level the health service offered at the hospital from the perspectives of the patients.

To verify from hypothesis, means, standard deviations of sample individuals have been extracted on "responsiveness" Table 7 shows. 
Table 7. Means, standard deviations of sample individuals on "responsiveness"

\begin{tabular}{|c|c|c|c|c|c|}
\hline Rank & No. & Paragraph & Mean & Std. & Assessment degree \\
\hline 1 & 2 & $\begin{array}{l}\text { The hospital simplises work procedures as much as } \\
\text { possible to grantee speed and easy in offering } \\
\text { health service. }\end{array}$ & 3.71 & 0.80 & High \\
\hline 2 & 1 & $\begin{array}{l}\text { The patients are told about the time of service } \\
\text { providing accurately. }\end{array}$ & 3.61 & 0.77 & Medium \\
\hline 3 & 3 & The employees desire to help patients always. & 3.53 & 1.21 & Medium \\
\hline 4 & 4 & $\begin{array}{l}\text { Although employees are busy in offering services, } \\
\text { but they response with requests of patients } \\
\text { immediately. }\end{array}$ & 3.31 & 1.08 & Medium \\
\hline \multicolumn{3}{|c|}{ The dimension of "responsiveness" as a whole } & 3.54 & 0.80 & Medium \\
\hline
\end{tabular}

Table 7 shows that means of sample individuals were among (3.31-3.71). The highest was (2) The hospital simplises work procedures as much as possible to grantee speed and easy in offering health service the lowest (4) Although employees are busy in offering services, but they response with requests of patients immediately. Mean for the dimension as a whole (3.54) with medium degree.

One Sample T-test was applied on the dimension of "responsiveness". Table 8 shows that.

Table 8. Results of applying one sample t-test on the dimension of "responsiveness"

\begin{tabular}{|c|c|c|c|c|c|c|}
\hline Hypothesis & Sig. & $\mathbf{T}$ & Assessment deg. & Std. & Mean & Result \\
\hline $\begin{array}{l}\text { There is no statistical } \\
\text { significant at }(\alpha=0.05) \\
\text { between the main dimension } \\
\text { of responsiveness and the } \\
\text { level the health service } \\
\text { offered at the hospital from } \\
\text { the perspectives of the } \\
\text { patients. }\end{array}$ & 0.00 & 5.70 & Medium & 0.080 & 3.54 & $\begin{array}{l}\text { Hypothesis } \\
\text { accepted }\end{array}$ \\
\hline
\end{tabular}

Table 8 shows that there is a stastical significant at $(\alpha=0.05)$ between the main dimension of responsiveness and the level the health service offered at the hospital from the perspectives of the patients. (T) was (5.70) and it is a statistical significant. The standard mark for scale Quintet (3), mean was (3.80) and it is higher value than the standard mark. So, the hypothesis accepted by the proven formula not the alternative one.

The results related to sub- hypothesis (4):

there is no statistical significant at $(\alpha=0.05)$ between the main dimension of trust and the level the health service offered at the hospital from the perspectives of the patients.

To verify from hypothesis, means, standard deviations of sample individuals have been extracted on "trust" Table 9 shows: 
Table 9. Means, standard deviations of sample individuals on "trust"

\begin{tabular}{|c|c|c|c|c|c|}
\hline Rank & No. & Paragraph & Mean & Std. & Assessment degree \\
\hline 1 & 1 & $\begin{array}{l}\text { The patients trust in the skills and qualifications of } \\
\text { health staff (medical, nursing, etc..) }\end{array}$ & 4.13 & 0.56 & High \\
\hline 2 & 2 & $\begin{array}{l}\text { Patients feel save when dealing with employees of } \\
\text { hospital. }\end{array}$ & 3.91 & 0.74 & High \\
\hline 3 & 3 & $\begin{array}{l}\text { The behavior of employees seem good with } \\
\text { patients }\end{array}$ & 3.90 & 0.80 & High \\
\hline 4 & 4 & Hospital keeps confidential information of patients & 3.84 & 0.75 & High \\
\hline \multicolumn{3}{|c|}{ The dimension of "trust" as a whole } & 3.95 & 0.55 & High \\
\hline
\end{tabular}

Table 9 shows that means of sample individuals were among (3.84-4.13). The highest was (1) The patients trust in the skills and qualifications of health staff (medical, nursing, etc..), mean was (4.13). The lowest (4) Hospital keeps confidential information of patients (3.84). Mean for the dimension as a whole (3.95) with high degree.

One Sample T-test was applied on the dimension of "trust". Table 10 shows that:

Table 10. Results of applying once sample T-test on the dimension of "trust"

\begin{tabular}{|c|c|c|c|c|c|c|}
\hline Hypothesis & Sig. & $\mathbf{T}$ & $\begin{array}{c}\text { Assessment } \\
\text { deg. }\end{array}$ & Std. & Mean & Result \\
\hline $\begin{array}{l}\text { There is no statistical significant at }(\alpha=0.05) \text { between the main } \\
\text { dimension of trust and the level the health service offered at the hospital } \\
\text { from the perspectives of the patients. }\end{array}$ & 0.00 & 14.36 & High & 0.55 & 3.95 & $\begin{array}{c}\text { Hypothesis } \\
\text { accepted }\end{array}$ \\
\hline
\end{tabular}

Table 10 shows that there is a stastical significant at $(\alpha=0.05)$ between the main dimension of trust and the level the health service offered at the hospital from the perspectives of the patients. (T) was (14.36) and it is a statistical significant. The standard mark for scale Quintet (3), mean was (3.95) and it is higher value than the standard mark. So, the hypothesis accepted by the proven formula not the alternative one.

The results related to sub- hypothesis (5):

there is no statistical significant at $(\alpha=0.05)$ between the main dimension of empathy and the level the health service offered at the hospital from the perspectives of the patients.

To verify from hypothesis, means, standard deviations of sample individuals have been extracted on "empathy" Table 11 shows:

Table 11. Means, standard deviations of sample individuals on "empathy"

\begin{tabular}{|c|c|c|c|c|c|}
\hline Rank & No. & $\begin{array}{c}\text { Paragraph } \\
\end{array}$ & Mean & Std. & Assessment degree \\
\hline 1 & 5 & $\begin{array}{l}\text { The hospital is keen to respect the ethics of career } \\
\text { in all areas }\end{array}$ & 3.87 & 0.88 & High \\
\hline 2 & 2 & $\begin{array}{l}\text { The employees owns realization and knowledge in } \\
\text { the needs of patients }\end{array}$ & 3.71 & 1.05 & High \\
\hline 3 & 6 & Physician listen carefully to patients' complaints. & 3.61 & 0.91 & Medium \\
\hline 4 & 1 & Physician is interested carefully and individually & 3.53 & 1.13 & Medium \\
\hline 5 & 4 & $\begin{array}{l}\text { The management of hospital offers the best for } \\
\text { patients. }\end{array}$ & 3.43 & 0.83 & Medium \\
\hline 6 & 3 & $\begin{array}{l}\text { The patients are described by joyfulness and } \\
\text { faithfulness in dealing with patients }\end{array}$ & 3.40 & 1.06 & Medium \\
\hline 7 & 7 & The health diagnosis time fits all patients. & 3.34 & 0.90 & Medium \\
\hline \multicolumn{3}{|c|}{ The dimension of "empathy" as a whole } & 3.56 & 0.78 & Medium \\
\hline
\end{tabular}

Table 11 shows that means of sample individuals were among (3.34-3.87). The highest was (5) The hospital is keen to respect the ethics of career in all areas, mean was (3.87). The lowest (7) The health diagnosis time fits all 
patients (3.34). Mean for the dimension as a whole (3.56) with medium degree.

One Sample T-test was applied on the dimension of "empathy". Table 12 shows that:

Table 12. Results of applying one sample t-test on the dimension of "empathy"

\begin{tabular}{lcccccc}
\multicolumn{1}{c}{ Hypothesis } & Sig. & T & $\begin{array}{c}\text { Assessment } \\
\text { deg. }\end{array}$ & Std. & Mean & Result \\
\hline $\begin{array}{l}\text { There is no statistical significant at }(\alpha=0.05) \text { between the main dimension } \\
\text { of empathy and the level the health service offered at the hospital from the } \\
\text { perspectives of the patients. }\end{array}$ & 0.00 & 5.97 & Medium & 0.78 & 3.56 & $\begin{array}{c}\text { Hypothesis } \\
\text { accepted }\end{array}$ \\
\hline
\end{tabular}

Table 12 shows that there is a statistical significant at $(\alpha=0.05)$ between the main dimension of empathy and the level the health service offered at the hospital from the perspectives of the patients. (T) was (5.97) and it is a statistical significant. The standard mark for scale Quintet (3), mean was (3.56) and it is higher value than the standard mark. So, the hypothesis accepted by the proven formula not the alternative one.

Verifying the main hypothesis, we found that there is no statistical significant at $(\alpha=0.05)$ between the main dimension of services quality (tangibility, reliability, responsiveness, trust, and empathy) and the level the health service offered at the hospital from the perspectives of the patients. One Sample T-test was applied on the tool as a whole. Table (13) shows that:

Table 13. The result of applying (one sample t-test)

\begin{tabular}{|c|c|c|c|c|c|c|}
\hline Hypothesis & Sig. & $\mathbf{T}$ & $\begin{array}{c}\text { Assessment } \\
\text { deg. }\end{array}$ & Std. & Mean & Result \\
\hline $\begin{array}{l}\text { There is no statistical significant at }(\alpha=0.05) \text { between the main dimensions } \\
\text { of services quality (tangibility, reliability, responsiveness, trust, and } \\
\text { empathy) and the level the health service offered at the hospital from the } \\
\text { perspectives of the patients. }\end{array}$ & 0.00 & 11.71 & High & 0.64 & 3.81 & $\begin{array}{c}\text { Hypothesis } \\
\text { accepted }\end{array}$ \\
\hline
\end{tabular}

Table 13 shows that there is a stastical significant at $(\alpha=0.05)$ among the main dimensions of services quality (tangibility, reliability, responsiveness, trust, and the level the health service offered at the hospital from the perspectives of the patients. (T) was (11.71) and it is a statistical significant. The standard mark for scale Quintet (3), mean was (3.81) and it is higher value than the standard mark. So, the hypothesis accepted by the proven formula not the alternative one

\section{Conclusion: Results and Recommendations}

\subsection{The Results}

The study has proven that there is a statistical significant among the variables of the study including the dimensions of service quality represented by (tangibility, reliability, responsiveness, trust, and empathy) and the level of health service quality offered.

- It has also proven that there is no gap between the health services expected and that are offered by Jordanian health sector at King Abdullah University Hospital.

- The procedures of work are facilitated as much as possible and the continuous to cooperate with the patients and this is what reflects the following response.

- The study has reached that there is a relative variation among the dimensions of health service quality on the level of health service offering in the sector from the perspectives of patients. They were ordered respectively: tangibility, trust, reliability, empathy, and responsiveness.

\subsection{Recommendations and Suggestions}

- The researchers have recommended in the necessity of continuous in adopting the strategy of health service quality.

- The institutions of health field must work to develop the quality of its health services because it grantees the statisfication of customers and their loyalty as result. 
- Conducting developments in the physical environments, in health institutions, and to interest in physical dimensions in the process of service offered.

- Working on developing the level of reliability related to hospital response for the problems and the questions of reviewers to grantee offer the services satisfies trust of patients and reviewers.

- Working to improve the level of empathy, responding to staff the health sector, and this requires increased attention to staff training and education to build the skills necessary to have in terms of patient services, and communication skills.

Finally, the researchers have recommended to continue conducting the objective researches to study and establish plans including evaluating quality dimensions in all service fields based on corrective scientific structures to facilitate service providing with high quality by decision makers.

\section{References}

Abdullah, A. M. (2013). Quality of service management. Warraq for Publishing and Distribution, Amman.

Al-Salme, A. (1995). The administrative policy in the information age, strange house for printing and publishing.

Alnasane, A. M. (2003). A specimen proposal to apply the philosophy of total quality in the institutions of higher education administration. Arab Forum to develop the performance of the faculties of management and trade in Arab universities, Aleppo.

Al-Towel, A. Q. (2010). The possibility of application of total quality management in hospitals. Rafidain magazine, Faculty of Management and Economics, Iraq.

Anezi, S. J. A. H. (2011). The requirements and constraints of the application of total quality management in the Medical Affairs Directorate General of Border Guard Administration. Master Thesis, Graduate School, Department of Administrative Sciences, University of Prince Naïf Military Sciences, Riyadh.

Aqili, O. W. (2001). The entrance to the methodology overall quality (point of view). Dar Wael for publication, Oman.

Ateeq, A. (2012). The quality of health services in the Algerian public institutions public hospital organization happy with the mandate of the case study. Master unpublished memorandum, Abu Bakr Belcaid University, Tlemcen.

Bakre, S. (2001). The planning and control university for publication. Alexandria.

Boukjana, J. (2010). The effect of the quality of health services on the degree of loyalty of patients in the University of Jordan Hospital "case”. Master Thesis, College of Graduate Studies, University of Jordan study.

Delilah, B. (2012). The necessity of activating the marketing orientation to get to the quality of service in public health institutions (study on the health sector in Algeria). Master Thesis, Faculty of Economic Sciences and facilitation Sciences, University of Algiers.

Diab, S. M. (2012). Measuring the quality of health services provided in the Jordanian government hospitals dimensions of patients and staff perspective. The Islamic University Journal of economic, administrative, Jordan, First Issue.

Hdad, O. I. (2009). Total Quality Management. Dar alfaker and Distributors, Oman,

Metras, A. E. D. A. (2009). The quality of health services and their impact on organizational effectiveness. Unpublished Master Thesis, Faculty of Management and Economics, University of Mosul

Sarhan, F. (2012). The overall global trends of modern quality management. Sharif Diamond library for publication and distribution, Cairo, 1st Floor Management .

Sufian, O. (2006). The role of marketing in the sector of health services from the perspective of beneficiaries (patients). Unpublished Master Thesis, Faculty of Economic Sciences and facilitation Sciences, University of Mohamed, Algeria. 


\section{Copyrights}

Copyright for this article is retained by the author(s), with first publication rights granted to the journal.

This is an open-access article distributed under the terms and conditions of the Creative Commons Attribution license (http://creativecommons.org/licenses/by/3.0/). 